\title{
Das mandäische Königsbuch. \\ Transskribiert, übersetzt und mit Anmerkungen versehen.
}

Von Sch. Ochser.

Das Stück, welches ich hiermit dem Leser vorlege, umfasst die letzten $15^{\mathrm{x}} / 2$ Seiten der Sidrā Rabba ed. PeterManN. Den Namen "Königsbuch" hat es seines Inhaltes wegen von $T_{H}$. NöLDEKe erhalten. Es ist eines der ältesten Kapitel in der mandäischen Literatur, in altem, von arabischen Idiomen freiem Dialekte gehalten, mit dem messenischen identifiziert, und reicht nicht später als böchstens bis in das 1 . Jahrzehnt des 8. Jahrhunderts $\mathrm{n}$. Chr. zurück; vgl. TH. NöLdeKe, Mand. Gramm. p. XXII. Das Königsbuch zerfällt in folgende Teile:

I. p. $378,29-381,9$. Geschichte des Weltalls von seiner Erschaffung durch Abatur und Petahil bis zum Ende der Sintflut.

a) p. 378, 40-379, 18. Die Erschaffung Adam's und Verteilung der Existenzdauer an die 7 Fixsterne und I 2 Planeten.

b) p. 379, 19-380, 7. Der erste Weltuntergang durch Schwert und Pest, der zweite durch Feuer (vgl. KA ${ }^{3}$ II, ${ }_{56} 6$ ) und Erschaffung von Šorbai und Šarhabiel, der Begründer des Menschengeschlechtes.

c) p. 380, 8-381, 9. Der Weltuntergang durch das Wasser, die Geschichte von Noah (vgl. Chworsonn, Ssabier II, VIII). 
Sch. Ochser, Das mandäische Königsbuch.

II. p. $381,10-382,12$. Vom Auftreten Jorba-Adonai's bis Gajmuraț.

a) p. $381,10-382,9$. Entstehung der Jahuțäer, ihre Knechtschaft in Egypten, ihre Flucht.

b) p. $382,10-382,12$. Auftreten und Wirken Christi. III. p. $382,13-384,16$. Persische Herrscherdynastien.

a) p. 382, 13-383, 9. Gajmurat bis Xurrah (Tab. 708, 13).

b) p. $383,10-383,15$. Verwechslung von Namensbegriffen, wie Salomo, Barkas und Senator.

c) p. 383, 16-18. Dynastie der Mirzond (Justr, Iran. Namenbuch).

d) p. $383,19-384,16$. Dynastie der Sassaniden bis Jezdegerd.

IV. p. 384, I 7-390, I1. Schilderung der Unglückszeit für das Land (die Welt) bis zu dem Auftreten der Araber (vgl. Mas'ū ūi II, 233 in Nöldeke's Gesch. der Perser und Araber z. Z. d. Sas., Leyden 1879), Verrohung und Falschheit unter den Menschen im Zeitalter der Araber.

V. p. 390, 12-392, 9. Apokalypse, die zukünftigen Grosskönige, Anbruch herrlicher Zeiten nach manigfachen Kriegen.

VI. p. 392, 10-394, 14. Das Weltende (vgl. Schürer, Gesch. II, 546).

a) p. $392,10-393,9$. Vorausgehende Naturerscheinungen.

b) p. 393, 10-393, 19. Der Sturz des Bel.

c) p. 393, 20-394, 4. Vernichtung der Welt durch den Leviatan.

d) p. 394, 5-14. Das Urteil der 'Utras. 


\section{Text und Uebersetzung. ${ }^{2}$ )}

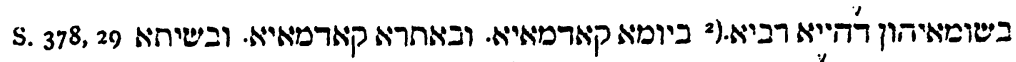

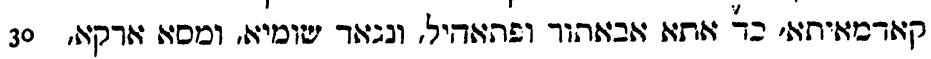

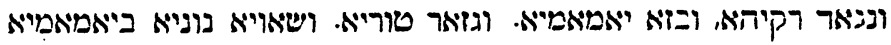

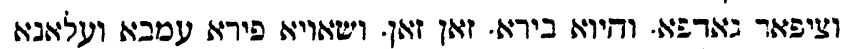

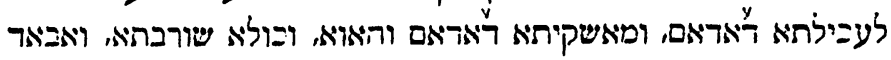

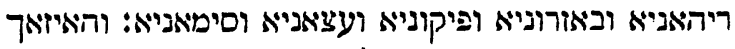

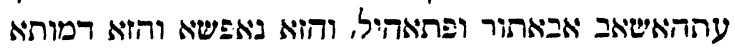

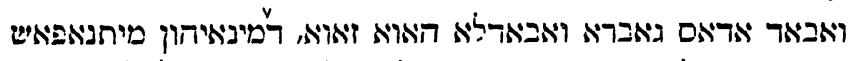

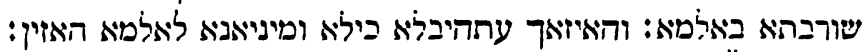

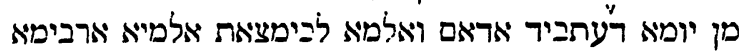
ותמאנאן אלפיא שניא האויא: והאייזאך עתהיב כעלא ומינימייאניא

Im Namen des grossen Lebens. Am ersten Tage, am ersten Orte und in der ersten Stunde [war's], als da kam Abatur und Petahil, und spannte aus den Himmel und verdichtete die Erde, und spannte aus das Firmament, und spaltete die Meere, und baute die Berge, und machte die Fische in den Meeren und die geflügelten Vögel und die Feldtiere verschiedener Art, und machte Früchte, Trauben und Bäume zur Nahrung des Adam, und zum Tranke des Adam und der Hawa, und seiner ganzen Nachkommenschaft, und schuf duftende [Kräuter] und Sämereien und Blumen und Bäume und Spezereien. Und hierauf beriet sich Abatur mit Petahil, und sah sich selbst und sah seine Gestalt, und schuf den Mann Adam, und machte ihm sein Weib Hawa, von denen sich ausbreitet das Geschlecht in der Welt. Und hierauf ward gegeben Mass und Zahl dieser Welt. Von dem Tage, da erschaffen ward Adam, bis zum Ende der Wesen sind es 480000 Jahre. Und hierauf ward gegeben Mass und Zahl

I) Zur besseren Uebersicht und leichteren Benülzung für den Leser ist hier der Peteraiann'sche Text wiederholt. Dieser wurde, da es unmöglich war, dem Herrn Verf. die Korrektur zugehen zu lassen, seitens der Redalktion kollationiert. - Es wäre auf's lebhafteste zu begrüssen, wenn die kurzen der Uebersetzung beigegebenen Anmerkungen zu ausführlicheren fachmännischen Aeusserungen über den interessanten Gegenstand veranlassten. - Red.

2) Siehe Brandt, Mand. Rel. p. 209. 
S. 379,

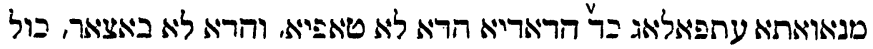

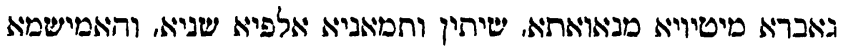

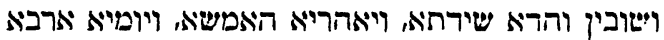
5

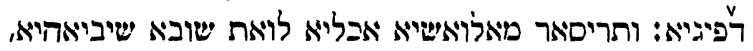

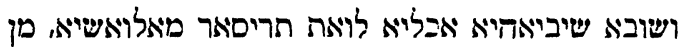

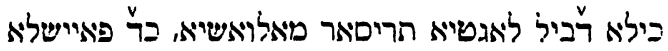

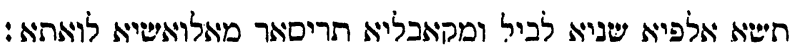

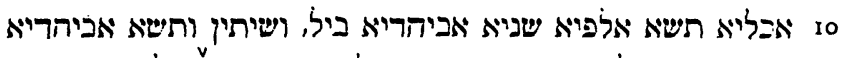

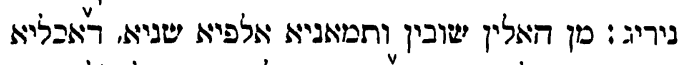

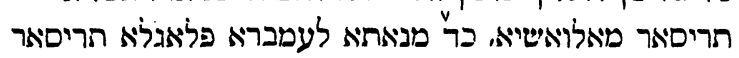

den sieben Sternen und den zwölf Führern, und ein Mass ward geteilt in sieben Teile so, dass unter einander einer nicht grösser ist, und der andere nicht geringer. An jeden gelangten als Gaben 68 ooo Jahre, und $57 \mathrm{I}$ Jahre, 5 Monate und 4 Tage, und sechs und eine halbe Stunde und vier Minuten und eine Sekunde und eine halbe Sekunde. Und die zwölf Zodiakalbilder dauern neben den sieben Sternen, und die sieben Sterne dauern neben den zwölf Zodiakalbildern. Von dem Masse des Bel nahmen die zwölf Zodiakalbilder, und da blieben 9000 Jahre dem Bel, so nahmen sie die zwölf Zodiakalbilder für sich. Sie herrschten 9000 Jahre mit Bel, und 69 mit Nirig. Von jenen 78000 Jahren, in welchen die zwölf Zodiakalbilder herrschten, zuerteilten sie dem Bocke als Gabe zwölf-

ז) שיאמייש, ליבאת ,סין, ביויאן, ביל ,נבו ,ניריז.

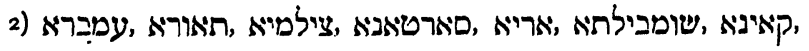

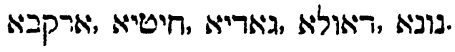




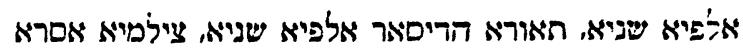

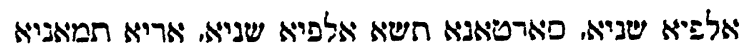

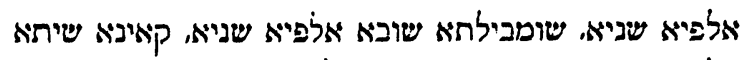

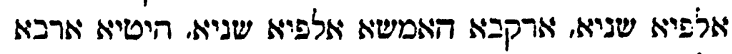

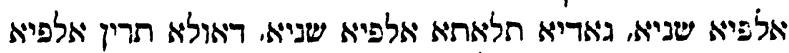

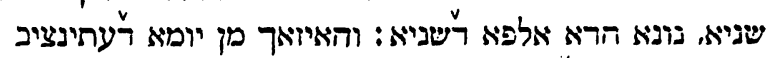

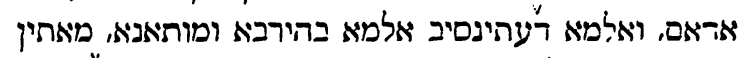

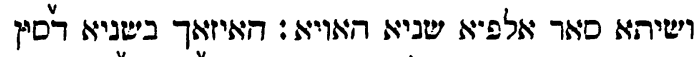

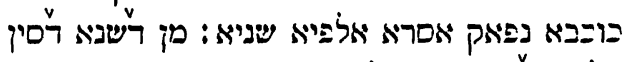

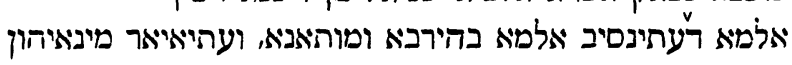

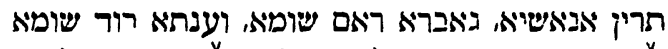

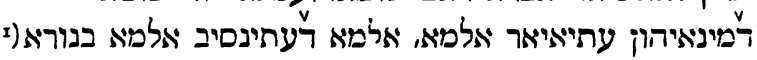

tausend Jahre, dem Stiere II 000 Jahre, dem Zilma 10000 Jahre, dem Krebse 9000 Jahre, dem Löwen 8000 Jahre, der Jungfrau 7000 Jahre, der Wage 6000 Jahre, dem Skorpion 5000 Jahre, dem Bogen 4000 Jahre, der Ziege 3000 Jahre; dem Eimer 2000 Jahre, dem Fische 1000 Jahre. Und von dem Tage an, da erschaffen ward Adam, bis dass die Welt hinweggerafft wird durch Schwert und Pest, sind es 260000 Jahre. Dann gehen vorüber in den Jahren des $\operatorname{Sin} 10000$ Jahre. Und von den Jahren des Sin, bis dass die Welt hingerafft wird durch Schwert und Pest, da werden ins Leben gerufen von ihnen $z$ wei Menschen, der Mann, dessen Name Ram ist, und ein Weib, deren Name Rud ist, aus denen die Welt ins Leben gerufen wird, bis dass hingerafft wird die Welt im Feuer,

1) Ueber den Weltbrand s. ZIMMeRN, KAT ${ }^{3}$ p. 560. 


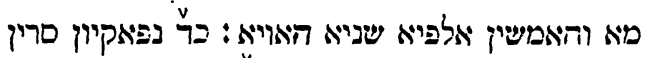
S. 380,1

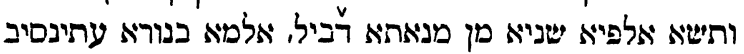

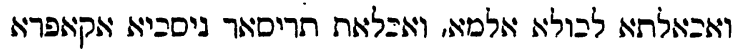

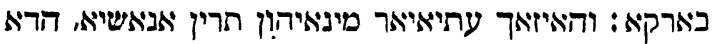
5

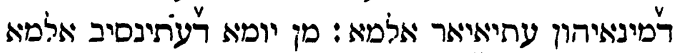

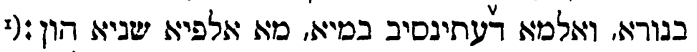

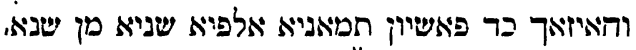

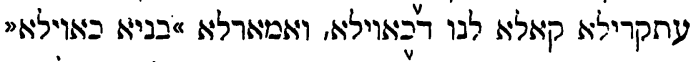

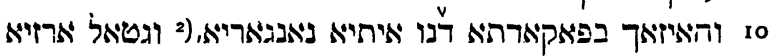

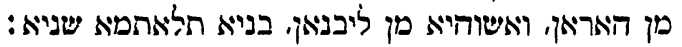
גטאר ביאוילא במאישיהתא תלאתמא אמייא, ופותיא מיאיא

werden es 150000 Jahre sein. Wenn ausgehen 29000 Jahre von dem Anteil des Bel, wird die Welt im Feuer hingerafft, das verzehret die ganze Welt, und verzehret die zwölf Metalle mit dem Staube der Arqa. Hierauf werden aus ihnen ins Leben gerufen zwei Menschen, ein Mann, dess Name ist Sorbai, und ein Weib, dess Name ist Šarhabiel, von ihnen wird die Welt ins Leben gerufen. Von dem Tage an, da die Welt hinweggerafft wird im Feuer, bis dass sie hingerafft wird im Wasser, sind es I00000 Jahre. Und da noch übrig bleiben 8000 Jahre von jenen Jahren, da rufet eine Stimme den $\mathrm{Nu}$ der Arche und spricht zu ihm: »Baue eine Arche«. Und hierauf kamen im Auftrage des $\mathrm{Nu}$ Baumeister, und die fällten Zedern vom Haran und Fichten vom Libanon, sie bauten 300 Jahre. Sie zimmerten die Arche nach ihrer Länge 300 Ellen, nach der Breite

1) Šặrastani 36425 , Chaldäer 9977, Dabistân: jeder Planet für sich 1600 Jahre, Hesiod: alle vier Weltalter 18028, Aegypten $36525=25 \times$ 146r Sotis-Daten.

2) Gilgameš-Epos; s. Gunker, Sch. w. Ch. Anhang p. 424. 
האמשין אמיא. וריאומא הלאתין אמיא: והאיזאך לגיאט

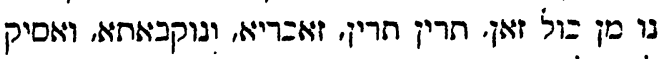

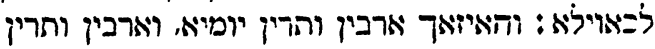

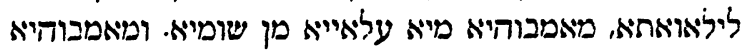

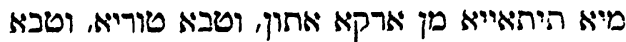

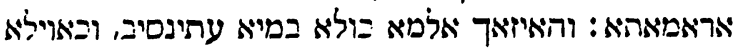

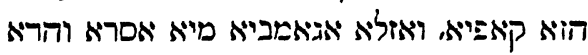

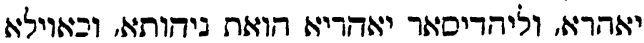

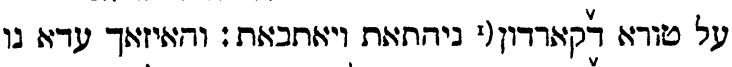

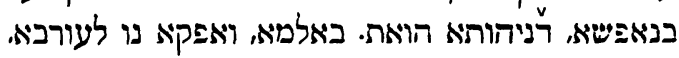

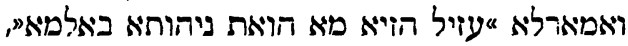

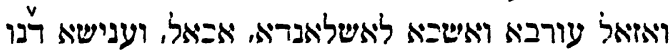

50 Ellen und nach der Höhe 30 Ellen; hierauf nahm $\mathrm{Nu}$ von jeder Art je zwei, ein Männchen und ein Weibchen, und führte sie hinein in die Arche. Und hierauf kamen zwei und vierzig Tage und zwei und vięrzig Nächte die obersten Wasserwogen vom Himmel und die untersten Wasserwogen von der Arqa und versenkten die Berge, und versenkten die Höhen. Und hierauf wurde die ganze Welt im Wasser dahingerafft, und die Arche schwebte und ging über die Wasserwogen elf Monate, und nach elf Monaten ward Ruhe, und die Arche senkte sich und blieb ruhen auf dem Berge Qardon. Und da wusste $\mathrm{Nu}$ in seinem Innern, dass Ruhe geworden in der Welt, und da schickte $\mathrm{Nu}$ den Raben hinaus und sprach zu ihm: „Geh', schaue ob schon Ruhe ward in der Welt!« Und da ging der Rabe und fand einen Leichnam, er ass [von ihm] und vergass, was $\mathrm{Nu}$

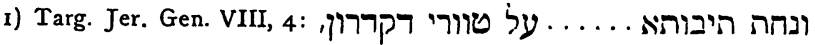
.... [Vgl. Schatzhöhle II, 94 f. - Red.] 


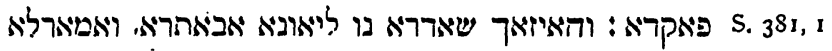

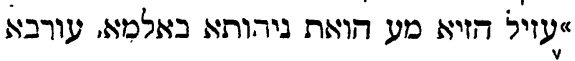

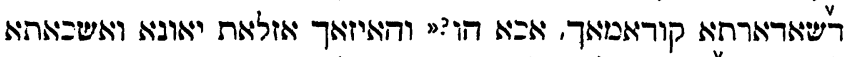

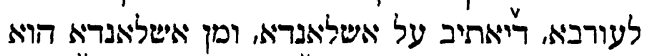

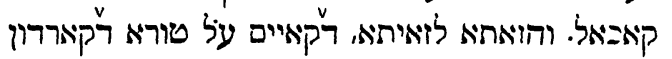

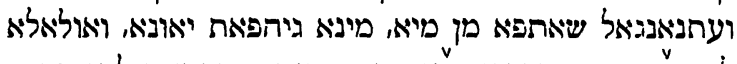

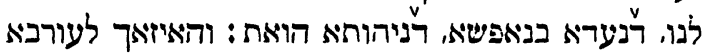

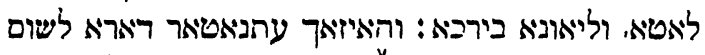

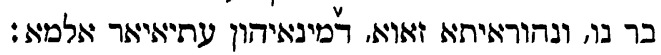

10

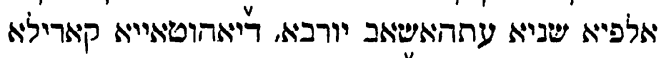

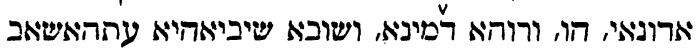

ihm befohlen. Hierauf sandte $\mathrm{Nu}$ die Taube ihm nach und sprach zu ihr: „Geh, schaue, ob schon Ruhe ward in der Welt; wo ist der Rabe, den ich vor dir geschickt? " Und hierauf ging die Taube und fand den Raben, der da sass auf einem Leichnam, und von dem Leichnam frass. Und sie sah einen Oelbaum, der da stand auf dem Berge Qardon, und es ragte hervor ein Reis aus dem Wasser, von diesem brach die Taube und brachte es dem $\mathrm{Nu}$, auf dass er bei sich wisse, dass Ruhe geworden. Und hierauf fluchte er dem Raben und segnete die Taube. Und da wurde bewahrt das Geschlecht dem Sum, dem Sohne des $\mathrm{Nu}$, und seinem Weibe Nehoraita, von denen die Welt ins Leben gerufen. Und als dann verflossen 6000 Jahre, und geblieben waren 2000 Jahre, da beriet sich Jorba, den die Jahuțäer Adonai nennen, er und die Ruha mit ihm, und die sieben Sterne. Sie planten 


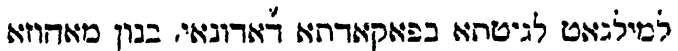

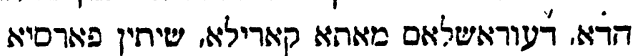

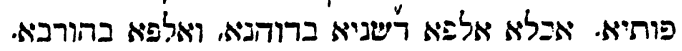

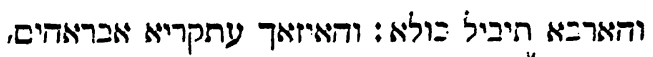

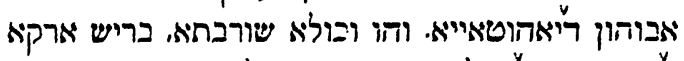

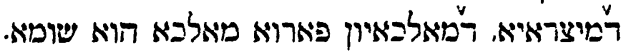

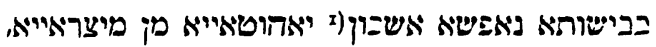

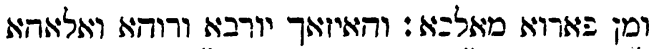

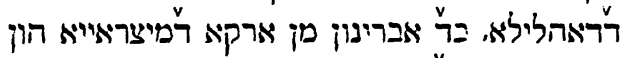

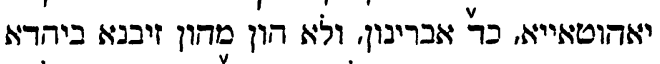

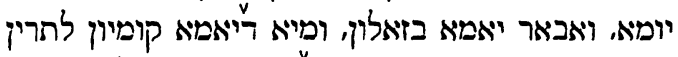

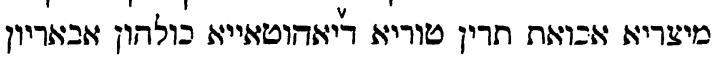

einen Plan auszuführen; im Auftrage des Adonai zu erbauen eine Stadt, die man Urašlam nannte. Sechzig $\mathrm{Pa-}$ rasangen in die Breite; sie dauerte 1000 Jahre in Blüte und tausend in Wüstenei: bis wüste wird die ganze Welt. Und hierauf ward gerufen Abrahim, der Vater der Jahuțäer. Und er und seine ganze Nachkommenschaft waren anfangs im Lande Mișraja, dessen König Parwa hiess; in grosser Not befanden sich die Jahuțäer bei den Mişräern, und bei ihrem König Parwa. Hierauf versetzten Jorba und Ruha und Alaha jene in Angst, so dass hinauszogen die Jahuțäer aus dem Lande Mișraia, und da sie hinauszogen auf einmal an einem Tage, wehrten jene sie nicht, und es verzog sich das Meer um ihretwillen, und die Wasser des Meeres erhoben sich zu zwei Grenzen, gleich wie zwei Berge, so dass alle Jahuțäer hinüberzogen

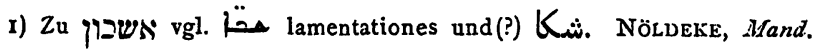
Gr. 104, Anm. 1 . 
S. 382, I

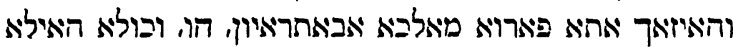

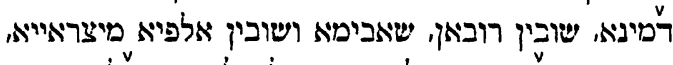

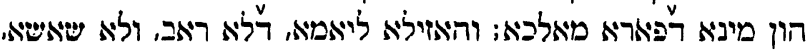

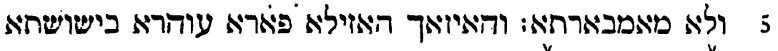

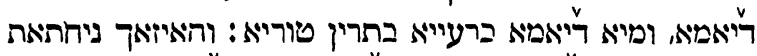

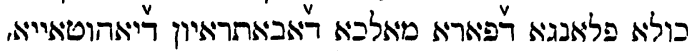

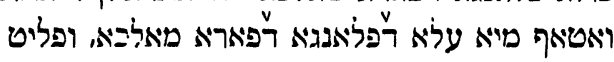

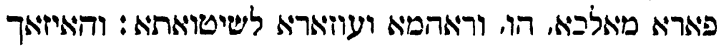

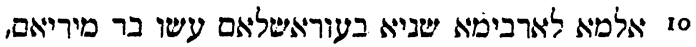

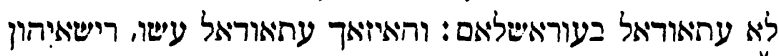

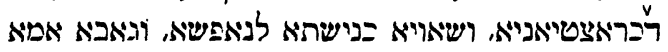

und dahingingen in die öde Wüste. Und hierauf zogen sie ein und wohnten in Urašlam. Hierauf kam König Parwa ihnen nach, er und sein ganzes Heer, das mit ihm war: 7770000 Mișräer waren mit König Parwa; Und er sah das Meer, das nicht gross und nicht aufgeregt war, und keine Ueberfuhr hatte. Und hierauf erblickte Para einen trockenen Weg des Meeres, und das Wasser des Meeres knieend in zwei Bergen. Da stieg hinein die ganze Phalanx des Königs Para den Jahuțäern nach, und es bedeckte das Wasser die Phalanx des Königs Para, und König Para rettete sich, er, seine Freunde und Helfer in der Verwirrung. Und vierhundert Jahre darauf wird in Jerusalem Ešu, der Sohn Mirjam's geboren. Und hierauf ward geboren Ešu, das Haupt der Christen, und er macht eine Versammlung für sich und wählt eine Nation für sich 


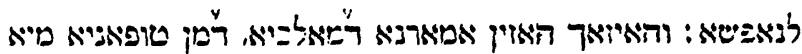

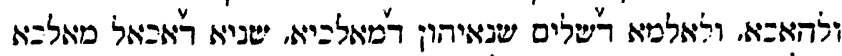

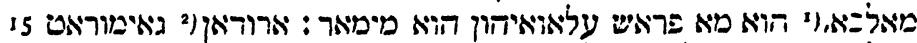

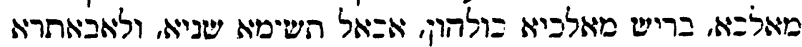

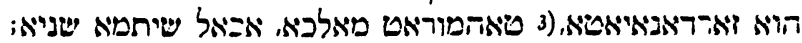

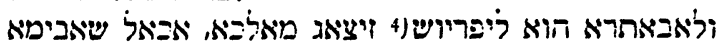

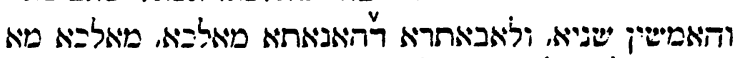

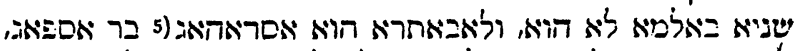

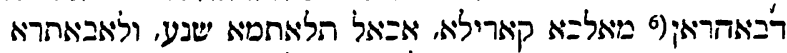

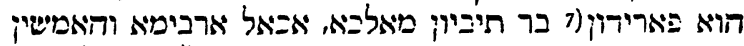

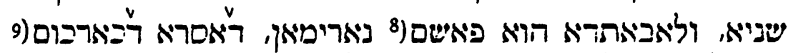

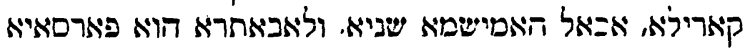

aus. Und nun wollen wir erzählen über die Könige, von der Sündflut bis jetzt, bis dass zu Ende sind die Jahre der Könige. Die Jahre, in denen jeder König regiert hat, und was von ihnen erzählt wird, soll hier gesagt werden. Arudan Gajmurat war König am Anfange aller Könige, er regierte 900 Jahre, und nach ihm war Zardanjața Tahmurat König, er regierte 600 . Und nach ihm war Lifroš-zișag König, er regierte 75.0 Jahre. Und nach diesem König war 100 Jahre kein König in der Welt. Und nach ihm war Asdahag, Sohn des Asfag, den man König Bahran nannte, er herrschte 300 Jahre, und nach ihm war Faridon, Sohn des Tibion König, der herrschte 450 Jahre, und nach ihm war Fašm Nahriman, den man Asra von Karkum nannte, er herrschte 500 Jahre, und nach ihm war der Perser aus'

r) Die geschichtlichen Angaben und die Reihenfolge sind verwirrt. Vgl. Justr, Altiran. Namcnsb. und die Königslisten daselbst [L.H. GRA Y]. - 2) Nach iranischen Quellen der erste Nensch; herrschte 30 Jahre [L. H. G.]. - 3) Die Epitheta nennen ihn azinavant »wachsam « und zënavand »bewaffnet « [L. H. G.]. - 4) Vielleicht Sisak, der Ahnherr der armenischen Fürsten [L. H. G.]. 5) Vielleicht Aži-Dahāka, der Dạhḥak der arabischen Schriftsteller [L. H. G.]. - 6) Sollte באורז mit Biwerasp und Biwer des Pehlevi identisch sein? - 7) Feridūn, der Neuperser, Besieger des Aži-Dahāka [L. H. G.]. 8) Sama Keresãspa, Nairimanas des Awesta [L. H. G.]; Sam Neriman, Vater des Zae, Vasall des Königs Minotschir. - 9) Karkum oder Krǘn, der Fleisch-

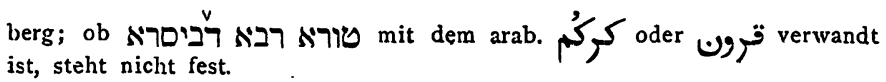




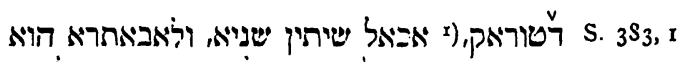

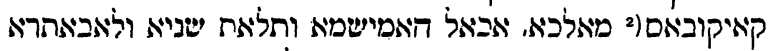

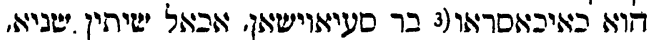

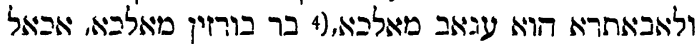

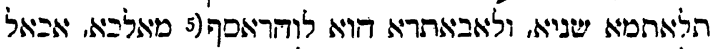

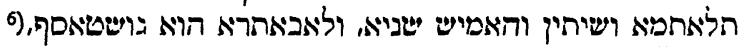

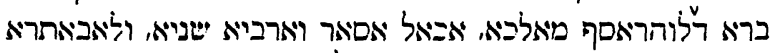

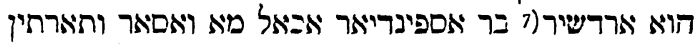

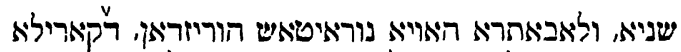

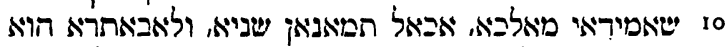

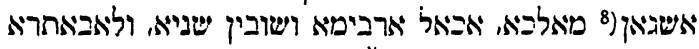

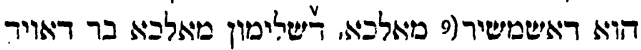

Turaq, der herrschte 60 Jahre, und nach ihm war Qaiqubas König, der herrschte 503 Jahre, und nach ihm war Kaikasraw, Sohn des Sejawischan, er herrschte 60 Jahre, und nach ihm war König 'Agab, Sohn des Königs Borzin, der herrschte 300 Jahre, und nach ihm war Lohrasp König, der herrschte 365 Jahre, und nach ihm war Guštasp. der Sohn des Lohrasp König, der herrschte I4 Jahre, und nach ihm war Ardešir, Sohn des Esfendear, der herrschte I 2 Jahre, und nach ihm war Nurajțš Horizdan, den man König Samidaj nannte, der herrschte 80 Jahre, und nach ihm war Ašgan König, der herrschte 470 Jahre, und nach ihm war Dašmšir König, den man König Šlimon, Sohn des Dawid

1) Zweiter Sohn des Ferïdūn; seine Vasallen nennen ihn 'Turan-Schal. (Shahname übers. von RückERT, ed. BAYER 1890, VI, 295 seq.)

2) Nachkomme Ferīdūn's, Nachfolger des Gersasp (ibid. XI, I).

3) Kava Huszawas, Sohn des Kava Syāvarsan des Aresta [L. H. G.].

4) Sohn des Burzin, Enkel des Keresāspa [L. H. G.].

5) Der bekannte König der Pehlevibücher [L. H. G.]. Vgl. auch JusTI, Gesch. d. alt. Pers. p. 35-36.

6) Vištāspa des Avesta [L. H. G.]; unter ihm tritt Zoroaster auf.

7) Sohn des Spentodata, Enkel des Vištãspa; fiel in der Schlacht gegen Arjasp [L. H. G.].

8) Begrüuder der Dynastie der Askanier [L. H. G.].

9) Jamsid [L. H. G.] 


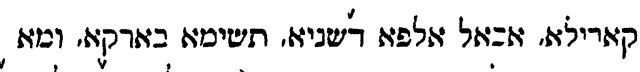

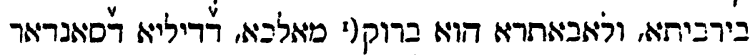

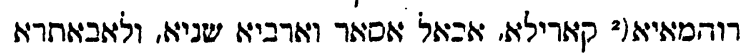

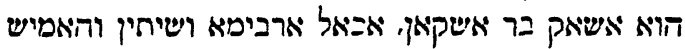

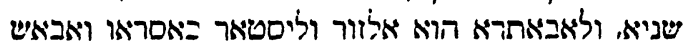

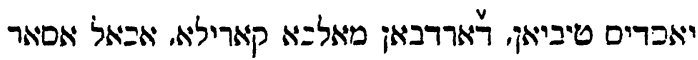

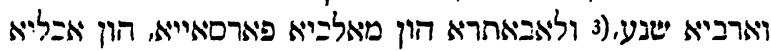

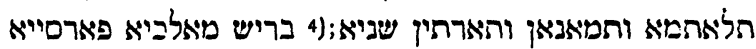

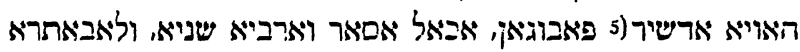

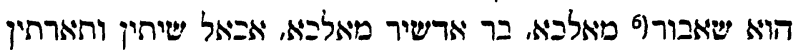

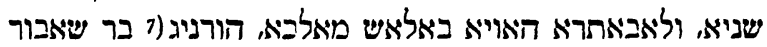

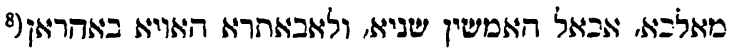

nannte, der herrschte rooo Jahre, 900 [Jahre] über Land und 10o. über das Meer, und nach ihm war Bruq König, der sich selber Sandar Rohmaja nannte, er herrschte 14 Jahre, und nach ihm war Ašaq, Sohn des Ašqan, der herrschte 465 Jahre, und nach ihm war Alzur, Lisțar, Kasraw, Abaš, Jasdis, Tibian, den man König Ardaban nannte, der herrschte I 4 Jahre, und nach ihm waren Perserkönige, welche 382 Jahre herrschten. An der Spitze der Perserkönige war Adšir Fabugan, er herrschte I4 Jahre und nach ihm war Sabur König, Sohn des Königs Adšir, er herrschte 62 Jahre, und nach ihm waren Balaš König, Hornig, Sohn Sabur's, des Königs, der herrschte 50 Jahre, und nach ihm war Bahran

1) Barkas Hamilkar.

2) Senator Romanus.

3) Jedwede Erinnerung an das Haus der Askanier scheint den Mandäern entschwunden.

4) Falsch, da das Sassanidenhaus 425 Jahre herrschte (226-651).

5) Herrschte $226-241$.

6) $\quad 241-272$, Interregnum 272-293, Narses 293-302.

7) $\rightarrow 302-309$.

8) V. $\quad 420-438$. 
S. 384 .

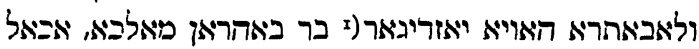

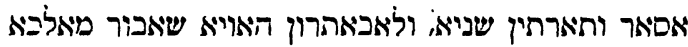

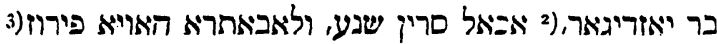
5

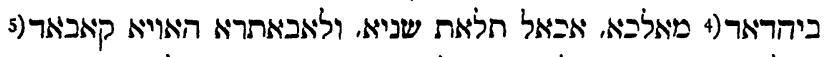

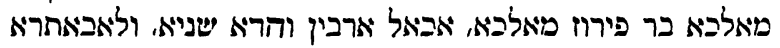

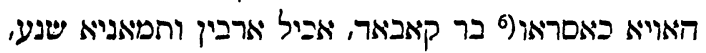

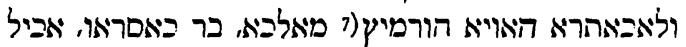

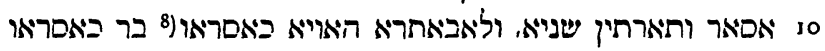

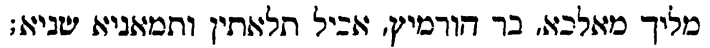

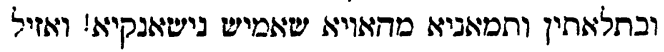

König, Sohn des Königs Sabur, der herrschte I 2 Jahre, und nach ihm war Jazdigar, Sohn des Bahran König, der herrschte 12 Jahre, und nach diesen war Šabur König, Sohn des Jazdigar, der herrschte 20 Jahre, und nach ihm war Firuz König, Sohn des Jazdigar, der herrschte 40 Jahre, und nach ihm war Bihdad König, der herrschte 3 Jahre, und nach ihm war Qobad König, Sohn des Königs Firuz, der herrschte 4I Jahre, und nach ihm war Kasraw, Sohn des Qobad, der herrschte 48 Jahre, und nach ihm war Hormiş König, Sohn des Kasraw, der herrschte 12 Jahre, und nach ihm war Kasraw, Sohn des Kasraw König der Könige, Sohn des Hormis, der herrschte 38 Jahre. Und im 38. Jahre hatte die Sonne Zeichen, da ging
I) II. herrschte $438-457$.
2) I., $399-420$.
3), $459-484$.
4) , $284-488$.
5) $\rightarrow 488-531$.
6) $\quad, \quad 531-578$.
7) $\quad 578-590$.
8) $\quad 590-628$. 


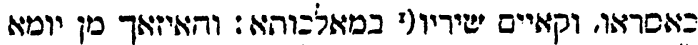

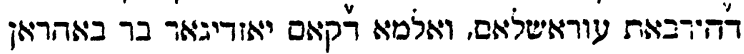

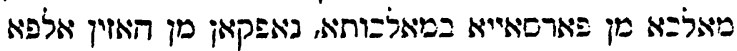

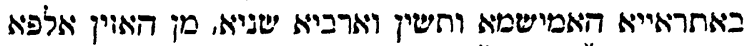

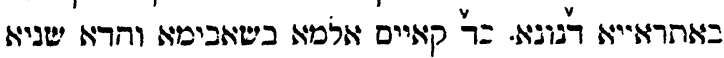

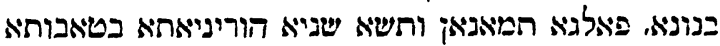
ובישותא יאתבאו שנייא עמאתין ויאסאר, עמיר עליאויאיהון.

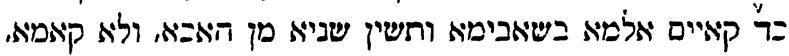

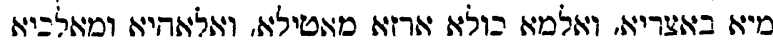

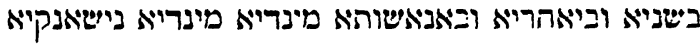

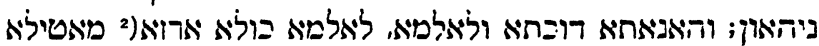

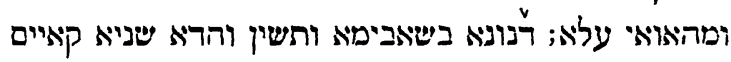

Kasraw und setzte ein den Širuje in sein Reich. Und siehe, von dem Tage an, da verwüstet ward Jerusalem, bis dass erstanden war Jazdigar, Sohn des Bahran, König der Perser in seinem Rejche, verflossen von diesen tausend 594 Jahre, von diesen letzten tausend Jahren der Fische. $\mathrm{Da}$ die Welt nun steht im jor. Jahre, teilt sie sich in 8I Jahre im Wohlstande, und im Elend bleibt sie 210 Jahre. Ueber sie ward gesagt: Wenn die Welt im 790 Jahre von da an besteht, hört sie auf. Das Wasser nimmt ab, und eine Dürre bemächtigt sich der ganzen Welt, und die Alahas und die Könige werden nach Jahren und Monaten und in ihren Familien nach und nach zu [abschreckeriden] Zeichen. Und diesen Ort wird gleich der ganzen Welt die Dürre erreichen. Und es wird geschehen, dass wenn die Fische im 79r. Jahre stehen,

1) Herrschte von 628 .

2) Die Pest unter Šerŏe. Nach Mas. II, 233 soll sie die Hälfte von allen Einwohnern hinweggerafft haben. Nöldeke, Gesch. d. Fers. u. Arab. Leyden 1879. 


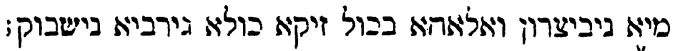

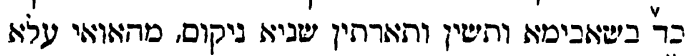

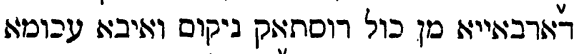

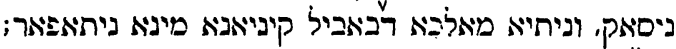
5

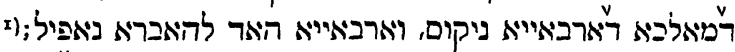

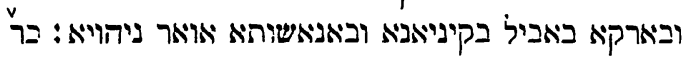

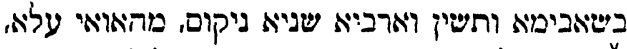

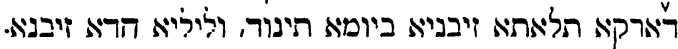

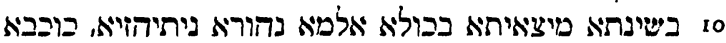

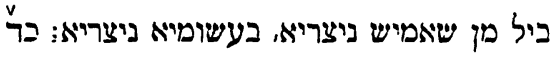

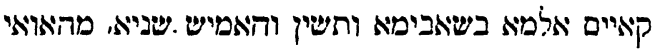

die Wasser abnehmen werden und Alaha alle Winde des ganzen Nordens loslassen wird. So sie im 792. Jahre stehen, wird es geschehen, dass die Araber sich von jedem Platze erheben werden, und ein schwarzer Nebel wird aufsteigen und kommen, dem Könige von Babel wird jeder Erwerb vernichtet. Und so sie im 793. Jahre stehen, wird es geschehen, dass der Araberkönig sich erhebt, und die Araber fallen einer über den anderen. Und im Lande Babel wird im Gewerbe und in den Familien eine Verwüstung entstehen. So sie im 794. Jahre stehen, wird es geschehen, dass die Erde dreimal im Tage beben wird, und einmal in der Nacht. Im mittleren Jahre erscheinet in der ganzen Welt ein Licht, der Stern Bel wird vom Sameš festgehalten, am Himmel wird er festgehalten. So die Welt im 795. Jahre besteht, wird es

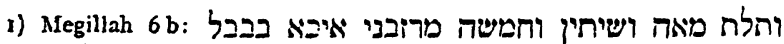

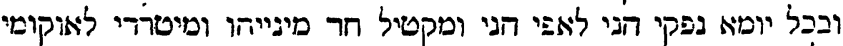




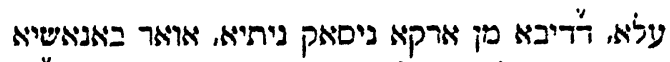

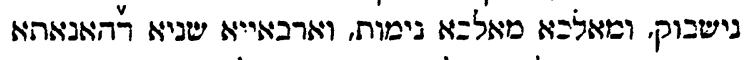

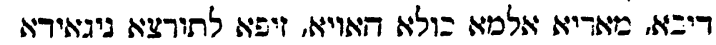

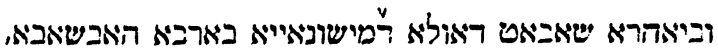

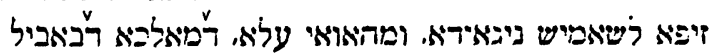

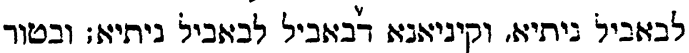

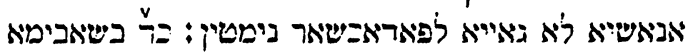

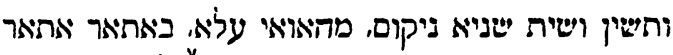

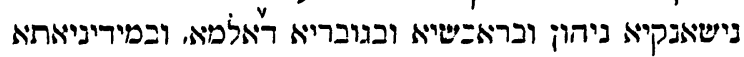

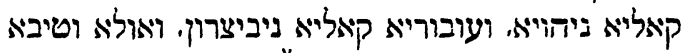

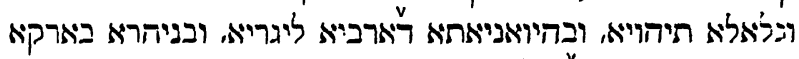

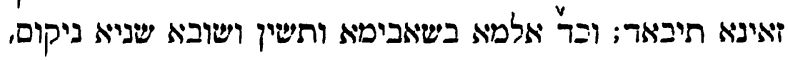

geschehen, dass ein Wolf von der Erde aufsteiget und kommet; Verwüstung unter den Menschen lässt er los, ein König tötet den [anderen] König, und die Araber werden in den vier Jahren jenes Wolfes die Herrn der ganzen Welt sein, Falschheit wird zur Aufrichtigkeit hingezogen. Und im Monate Sebat, wenn der Eimer sich ändert, am vierten Sonntag wird die Falschheit zum Šameš gezogen, und es wird geschehen, dass der König von Babel nach Babel kommt. Den Berg besteigen die Menschen nicht, sondern sie kommen zum Pad. So sie steht im 796. Jahre; wird es geschehen, dass an jeglichem Orte Zeichen entstehen an den Tieren und Menschen der Welt, und in den Städten werden Feuerbrände entstehen. Und die Ernten vermindern die Brände, und Unheil und Flut und eine Umwälzung wird entstehen. Auch an den vierfüssigen Tieren und in den Löchern der Erde gehen Waffen verloren. Und so die Welt im 797. Jahre steht, 
S. 386, I

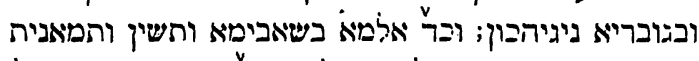

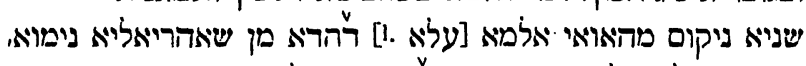

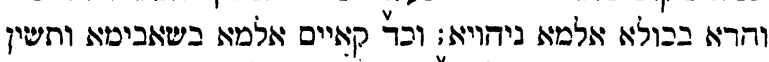

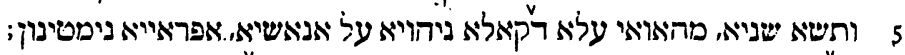

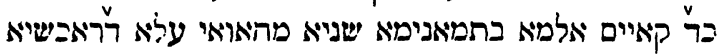

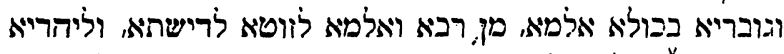

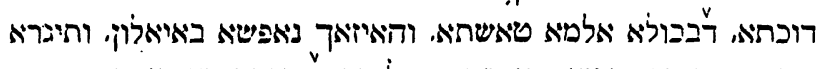

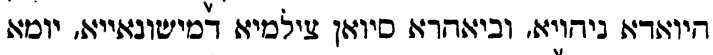
10

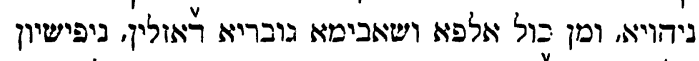

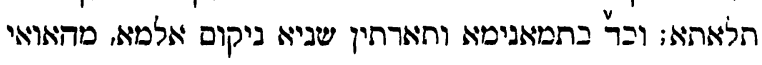

wird es geschehen, dass zwei Könige über einander lachen werden, und über die Maultiere und die Männer lachen sie. Und so die Welt im 798. Jahre besteht, wird es geschehen, dass einer von den zwei Königen sterben wird, und dass in der ganzen Welt einer sein wird. Und so die Welt im 799. Jahre besteht, wird es geschehen, dass eine Stimme an die Menschen ergehen wird, und dass die Afräer kommen. Und so die Welt im 80o. Jahre besteht, wird es geschehen, dass die Tiere und Menschen der ganzen Welt, Gross und Klein, sich in der Wüste an einem Orte sammeln, da in der ganzen Welt ein Getöse entsteht, und da suchen sie sich auf, und ein grosser Streit entsteht, und im Monate Siwan, da das Șilma sich ändert, am ersten Tage des Monates, in zwei und ein halb Stunden, wird ein glühender Kampf entstehen, und von 1700 Männern, die dorthin gehen, bleiben bloss drei. Und so die Welt im 802. Jahre steht, wird es geschehen, 


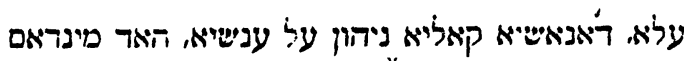

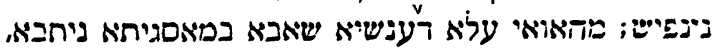

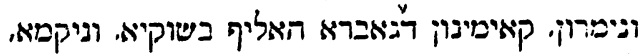

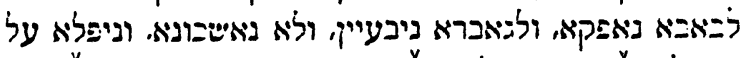

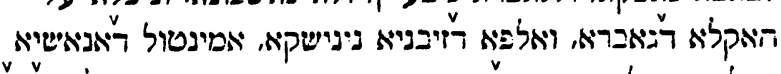

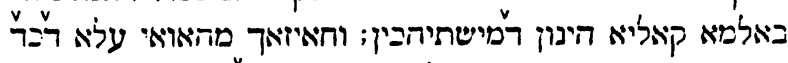

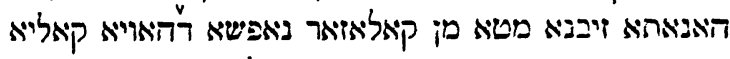

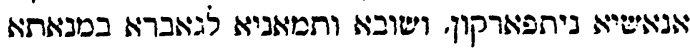

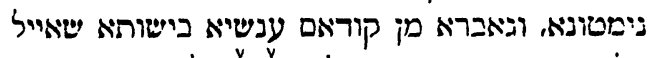

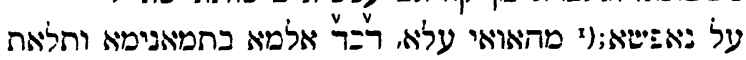

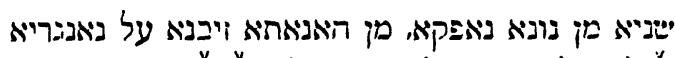

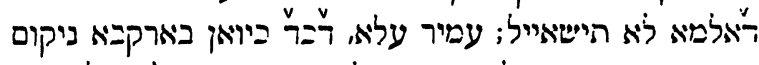

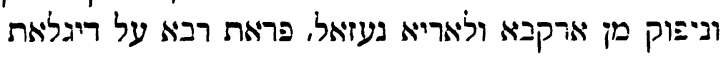

dass die Männer weniger sein werden als die Frauen, kaum einer bleibt zurück. Und es wird sein, dass sieben Frauen auf dem Wege sitzen werden und sagen: vir bleiben, bis ein Mann die Strasse passiert, dann erheben wir uns, gehen zum Fore hinaus, und suchen einen Mann und finden ihn nicht; dann fallen sie um den Hals eines Mannes und tausend Mal küssen sie ihn, weil es der Männer in der Welt $z u$ wenige gibt, dass sie gefunden werden. Und darauf wird es geschehen, wenn diese Zeit herankommt, da werden von den vielen Kämpfen, die stattfinden werden, nur wenige Männer unversehrt hervorgehen. Und sieben oder acht (Frauen) fallen dem Manne als Anteil zu, und der Mann wünscht über sich das Unglück wegen der Frauen. Es wird geschehen, dass wenn die Welt sich im 103. Jahre vom Fische (dem Zeichen) hinausgeht, dass von dieser Zeit an nicht mehr nach dem Handel in der Welt gefragt werden wird. Es ist darüber gesagt, dass wenn $\mathrm{Ke}$ wan im Skorpion steht, vom Skorpion hinausgeht und zum Löwen geht, der grosse Euphrat mit dem [in den] Diglat

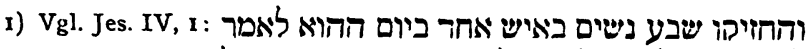

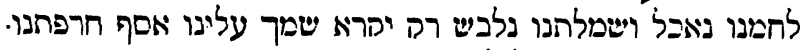


S. 387, ניפישוך, ובאביל ארקא האמשין שניא קודאם ארקא

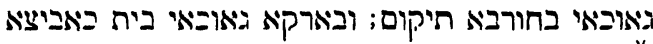

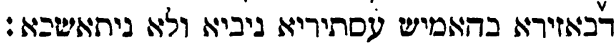

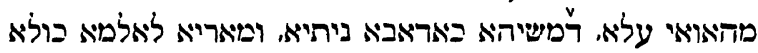
5

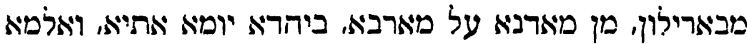

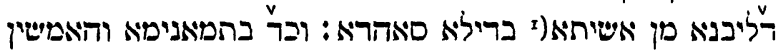

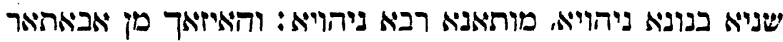

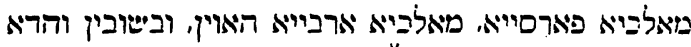

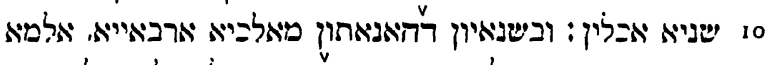

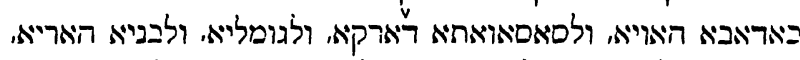

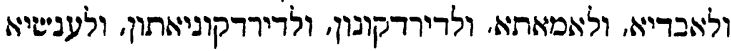

sich ausbreiten [ergiessen] wird, und das Land Babel wird 5o Jahre vor dem Lande Gaukai in Wüstenei liegen; und in dem Lande Gaukai wird ein Mass [kafiz] Samen für fünf Astarten gesucht und nicht gefunden. Es wird dann sein, dass der lügnerische Prophet kommt und Herr der ganzen Welt wird, er sitzt auf einem grossen Throne, auf ihm übt er Recht aus, und die Richter entfernt er. Von Ost bis nach West kommt er an einem Tage, bis dass die Ziegel aus der Wand gegen ihn zeugen. Und so [die Welt] im Fisch (dem Zeichen) sein wird, dann kommt eine grosse Pest. Dann wird nach der Herrschaft der Perser die der Araberkönige eintreten und 71 Jahre dauern. Und in den Jahren jener arabischen Könige wird die Welt lügenhaft sein, und für die Pferde und Kamele der edlen Zucht, die Knechte und Mägde, die kleinen (Knaben und Mädchen) und die Frauen

1) Vgl. Habak. II, 1 : ... בי אבן מקיר תזעק בי. 


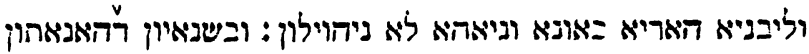

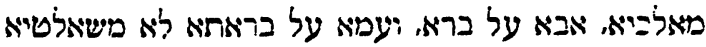

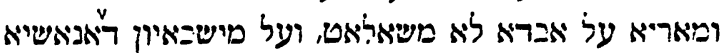

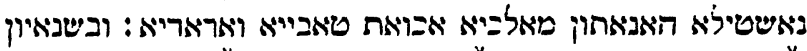

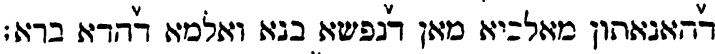

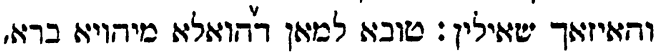

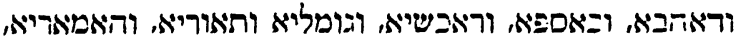

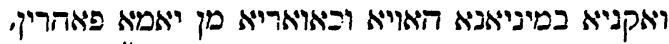

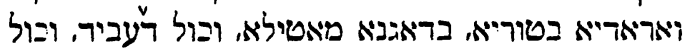

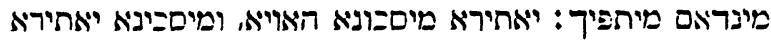

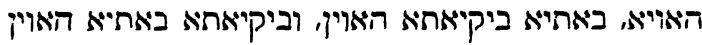

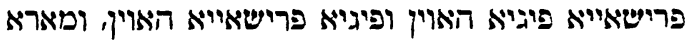

und die Edlen wird's keine Stütze [Ruhe] und Ruhe [Frieden] geben: Und in den Jahren jener Könige wird der Vater über den Sohn und die Mutter über ihre Tochter keine Herrschaft haben, und der Herr regiert nicht seinen Knecht, und die Haut des Menschen ziehen sie ab wie von Hirschen und Mauleseln. Und in den Jahren jener Könige, wenn einer nur einen einzigen Sohn zeuget und ihn hat, da ruft man: "Heil über den Mann, der einen Sohn gehabt hat! Und Gold und Silber und Maulesel und Kamele und Stiere und Esel und Kleinvieh in grosser Anzahl und Fische, die aus dem Meere fliegen, und Wildesel aus den Bergen bringt man ihm in die Ebene. Aber alles, was er erworben, wird ganz und gar nicht vernichtet. Der Reiche wird arm, der Arme reich, die Häuser werden Ruinen, die Ruinen Häuser, die Vornehmen zu Trabanten, die Trabanten zu Vornehmen, der Herr wird zum 
S. 328,

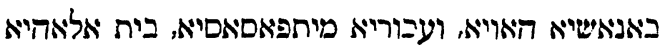

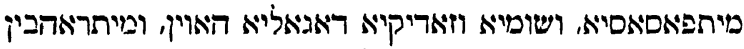

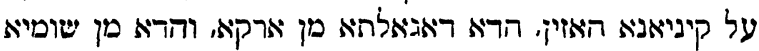

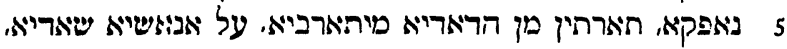

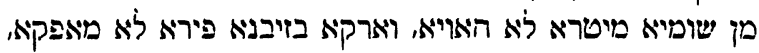

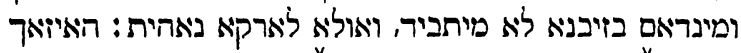

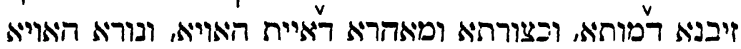

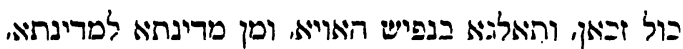

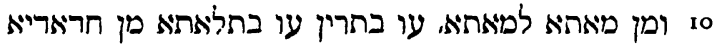

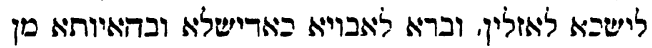

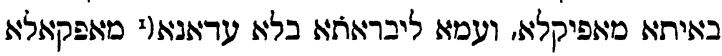

Knecht, der Knecht zum Edlen werden. Elend, Hinterlist und Falschheit wird unter den Menschen sein, die Altäre werden zerstört, die Alaha-Häuser vernichtet und die Namen der Aufrichtigen werden falsch werden, und man breitet sich aus bei diesem Gewerbe. Die eine Täuschung geht von Erden aus, die andere vom Himmel, beide nehmen durch einander $z u$ und werfen sich. über die Menschen, vom Himmel wird kein Regen sein, und die Erde bringt ihre Früchte zur Zeit nicht heraus, denn nichts reift zur Zeit, und Unglück steigt zur Erde nieder. Das wird eine Zeit des hereinbrechenden Todes, der Bedrängnis und der Krankheit werden, Feuer zu jeder Zeit und zahlreicher Schnee, und es wird nicht der Fall sein, dass man von Stadt zu Stadt, von Ort zu Ort, zu zwei oder drei miteinander gehn kann. Und der Sohn streitet mit dem Vater, und mit Gewalt vertreibt er ihn aus dem Hause, und die Mutter verjagt die Tochter vor der Zeit,

1) Vgl. Mika VII, 6: בי בן מנבל אב בת קמה באמה כלה בחמתה איבי איש אנשי ביתו. 
ולדינא רִיומאה ביומא מינא תיביא; ומאגושאייא וסאברי"ה

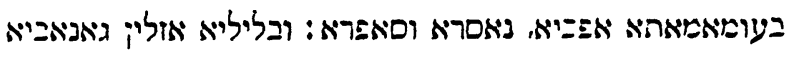
5

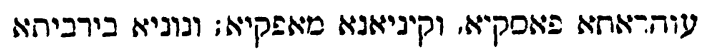

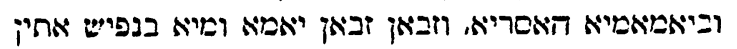

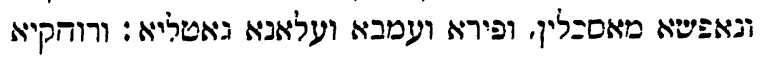

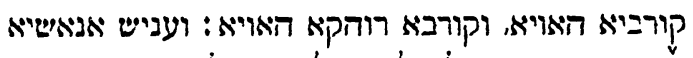

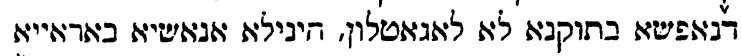

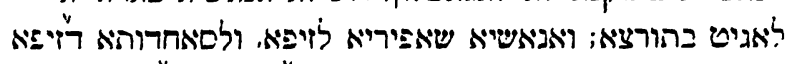

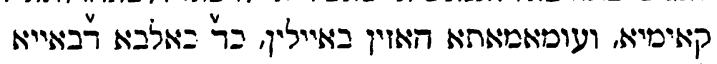

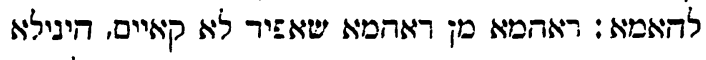

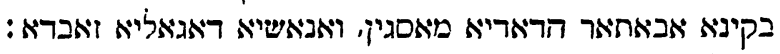

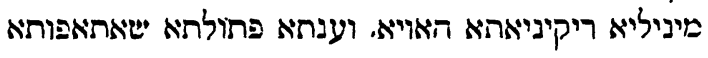

und zum täglichen Gerichte wird sie von ihr gebracht. Die Magier und die Schreiber verdrehen die Schwüre [tabcllio et scriba?, siehe NoRBERG]. In den Nächten streifen Diebe umher, schneiden die Wege ab und vertreiben den Erwerb. Die Fische werden in den Ozeanen und den Meeren weniger. Und zeitweise kommen Meer und Wasser in grosser Menge, vernichten Vieles und zerstören Früchte, Beeren und Blätter. Entfernungen werden Nähen, und Nähen Entfernungen. Die Frau nimmt die Männer nicht ihrer Schönheit wegen, da sie nur fremde Männer in Aufrichtigkeit nimmt. Schöne Männer stehen zur Falschheit und zur Aussage der Falschheit, und jene [falschen] Schwüre suchen sie, wie der Hund das Brot sucht; der Freund zeigt sich dem Freunde nicht aufrichtig, weil sie im Neid einander [ver]folgen und sich Betrügern anschliessen. Die Redensarten werden leer sein, und das Weib der Unverheirateten zur Gefährtin [Concubine] werden, 
S. 389, I גוילא; וענשיא לגאורא משאררא על גובריא, וענשיא

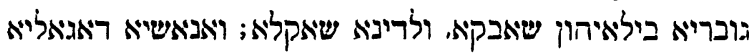

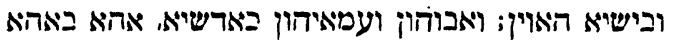

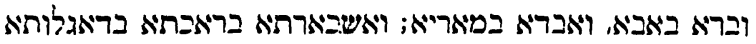

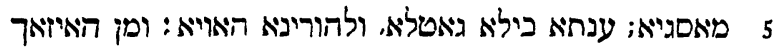

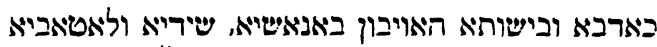

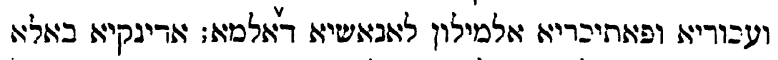

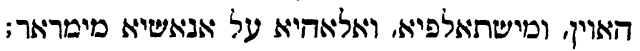

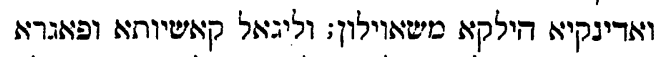

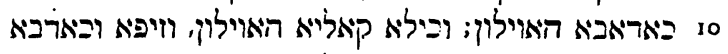

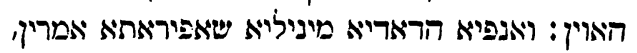

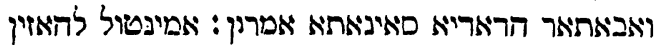

und die Weiber werden zu den Männern zum Ehebruch geschickt, die Weiber verlassen ihre Ehemänner und laden sie vor Gericht. Die Männer werden falsch und boshaft sein, ihre Väter und Mütter streiten, Bruder gegen Bruder und der Sohn gegen den Vater, der Knecht mit dem Herrn, in Schmutz, Hinterlist und Falschheit gehen sie einher [Norkerg]. Das Weib tötet ihren Mann und wird die (Frau) eines anderen. Und deswegen sind Lüge und Bosheit unter den Menschen. Dämone, Unholde, Unglücksteufel und Patikras verwitwen die Menschen der Welt. Die Reinen werden verschlungen und werden beraubt, und die Alahas, über die Menschen erbittert, setzen ihnen ein erhabenes [reines] Los vor, aber gar schnell erreichen sie das Unglück und Hinfälligkeit des Körpers, geringe Lebensdauer haben sie nebst Falschheit und Lüge. Ins Gesicht sagen sie sich schöne Worte und hinter dem Rücken Hässliches, denn dies, 


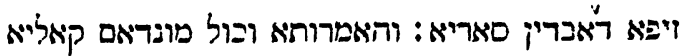

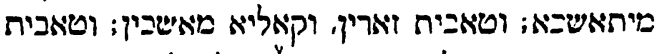

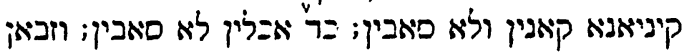

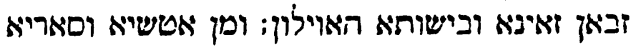

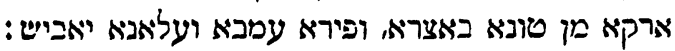

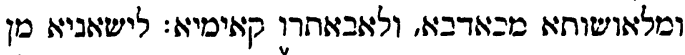

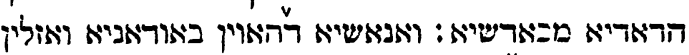

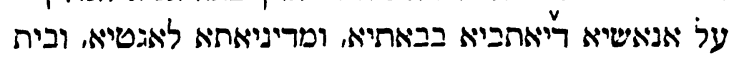

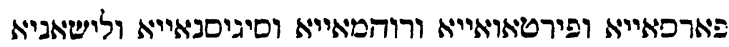

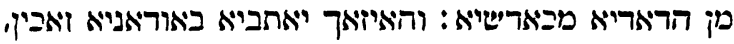

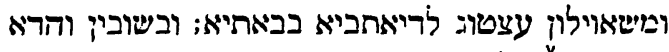

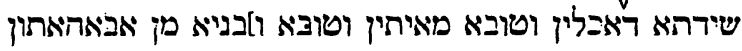

was sie falsch tun, stinkt. Wein und alles Andere wird nur wenig gefunden, viel säen sie und wenig ernten sie, sie machen zahlreiche Einkäufe und sättigen sich nicht, so sie essen, werden sie nicht satt, und von Zeit zu Zeit kommen über sie Schaden und Unglück; an Last der Gewächse und der Gerste [des Getreides] wird die Arqa geringer. Früchte, Beeren und Bäume trocknen ein. Die Sternzeichen stehen lügnerisch hinter einander, die Nationen kämpfen mit einander: Und die Menschen, die in den Wüsteneien sind, kommen über die Menschen, die in den Häusern sitzen, und erobern die Städte. Das Haus der Perser, Parter, Römer und Sigisnäer und [andere] Zungen liegen mit einander im Kampf, diejenigen aber aus der Wüste siegen und machen die, die in den Häusern sitzen, elend [NöLd., Mand. Gramın. XXX, I]. In den 7 I Jahren, während welcher diese herrschen, bringen sie Gutes. Und die Söhne versammeln sich mit den Vätern, 
S. 390, I

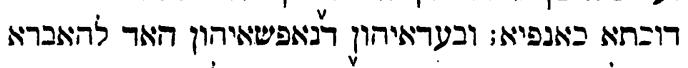

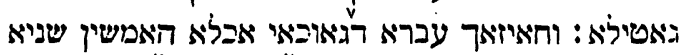

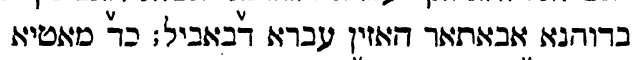

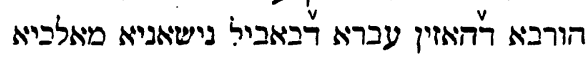

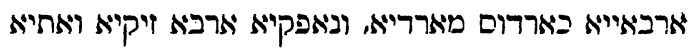

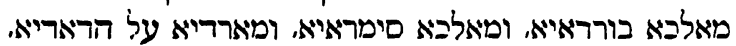

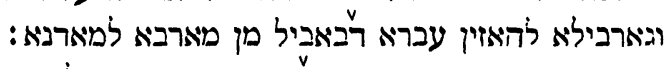

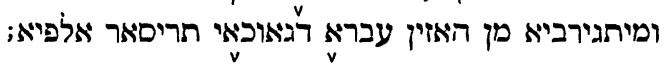

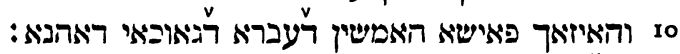

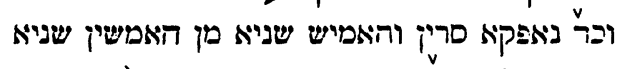

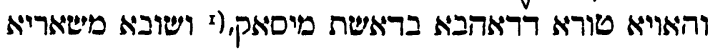

die Frauen mit den Männern und Brüder mit den Brüdern an einem Orte; mit eigenen Händen tötet [hierauf] einer den anderen. Deshalb überdauert der Teil von Gaukai den von Babel um 50 Jahre in Blüte. Wenn die Verwüstung über die Seite von Babel hereinbricht, ändert der Empörer Kardus die arabische Königs[linie]. Es erheben sich vier Winde, und herankommen der König der Burdäer und der König der Simräer, und die Empörer wider einander, und verwüsten den diesseitigen Teil von Babel von West gen Ost; die beraubt werden von dem Teile von Gaukai sind 12000 . Es bleibt nun der Teil von Gaukai 5o Jahre in Blüte. Wenn 25 von diesen 50 Jahren um sind, dann ist [entsteht] der Goldberg in der Einöde Misaq, und sieben Landstriche

I) Vielleicht zu lesen: מיסאן, Mesene; siehe jedoch NöLD, Mand. Gramm. XXVI. 


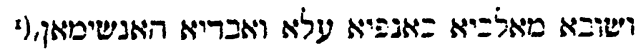

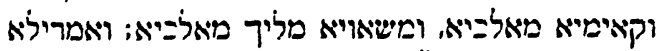

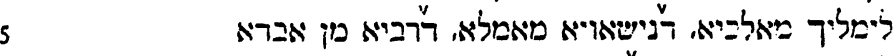

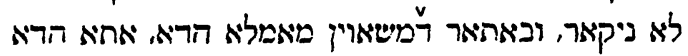

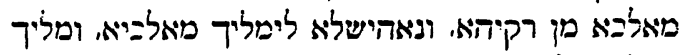

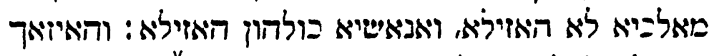

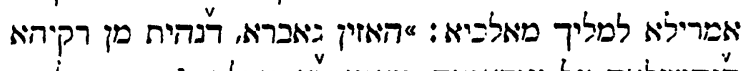

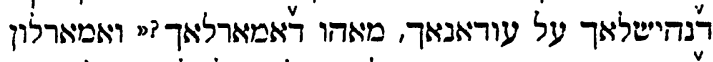

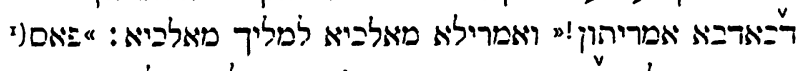

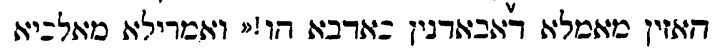

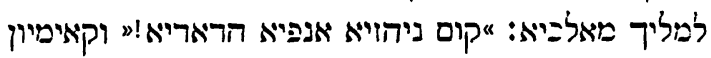

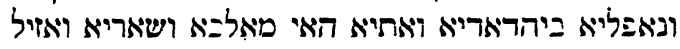

mit ihren sieben $\mathrm{Königen} \mathrm{versammeln} \mathrm{sich} \mathrm{auf} \mathrm{demselben}$ und machen eine Versammlung, und es erheben sich die Könige [zur Wahl] und wählen einen Grosskönig. Sie sprachen hierauf zum. Grosskönig, dass er ein Wort erlasse, dass der Herr nicht vom Sklaven geehrt werde, und nachdem sie das eine Wort erlassen, da kam ein König vom Himmel und flüsterte dem Grosskönig zu; der Grosskönig sah jenen aber gar nicht, während alle Menschen ihn ja sahen. Sie sprachen aber zum Grosskönig: „Dieser Mann, der vom Himmel heruntergestiegen und dir gewahrsagt [geflüstert] in dein $\mathrm{Ohr}$, was hat er dir gesagt?» Und er sprach zu ihnen: „Lüge saget ihr da!» $\mathrm{Da}$ sprachen die Könige zum Grosskönig: „Wohlan! das Wort, das wir erlassen, ist Lüge! « und da sprachen die Könige zum Grosskönig: ,Auf! wir wollen uns ins Gesicht blicken!s Und sie erheben sich, fallen gegen einander. Dieser König kam aber, ging hin und liess seine Pferde los

1) Siehe Nộdeke, Mand. Gramm. p. 205 und p. 305. 


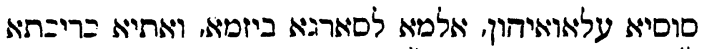
S. 391,1

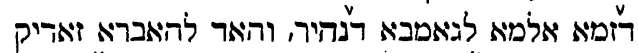

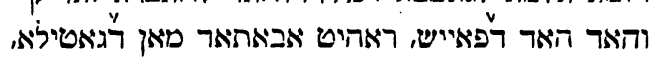

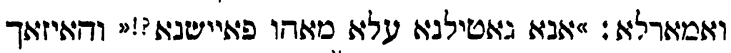

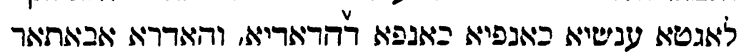

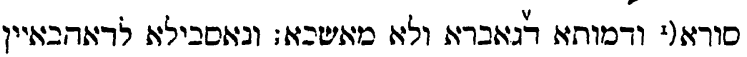

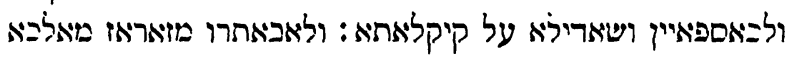

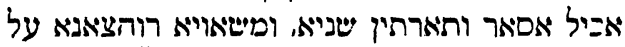

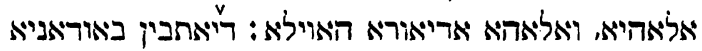

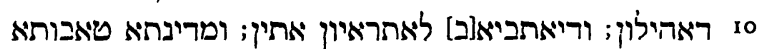

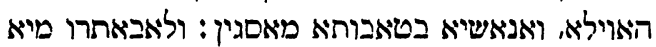

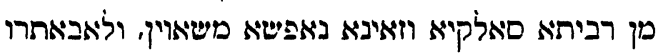

über sie bis zu den Zügeln im Blute, bis dass ein Blutstoss kommt und die Seite durchlöchert, dann [erst] werden sie sich wohlwollend, und jeder, der noch zurückgeblieben, eilt hin $z u$ dem, den er gemordet, und spricht zu ihm: "Ich bin der Mörder, weswegen bin ich denn geblieben? Hierauf nehmen sich die Weiber zusammen, machen mit einander eine Versammlung und suchen [umringen] nach der Macht und Gestalt eines Mannes und finden ihn nicht. Sie nehmen hierauf ihr Gold und Silber und werfen es auf den Scheiterhaufen. Es folgt dann der König Mzaraz, der zwölf Jahre herrscht, der setzt sein Vertrauen auf seine Götter, und die Götter sind ihm Helfer. Die Wüstenbewohner stösst er weg, und die an ihren Orten sitzen, kommen [heran]; ein Glück wird dem Lande zuteil, und die Menschen leben in Wohlhabenheit. Nach ihm steigt Wasser auf aus dem Meere, das vielen Schaden anrichtet. Und nach ihm

1) Siehe Nöldekr, Mand. Gramm. p. 235 Anm. I. 
מינדיאם הרא באלמא ד־באדאר קריאבא האויא, גובריא

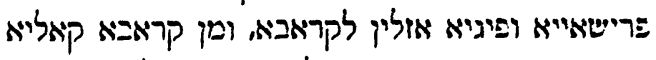

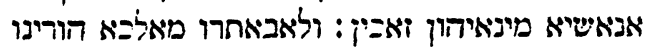

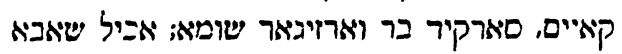

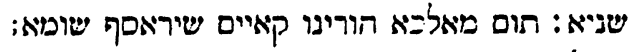

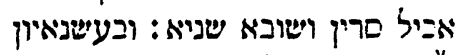

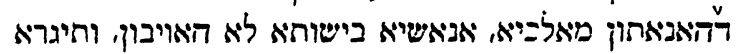

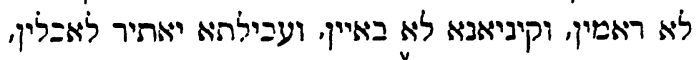

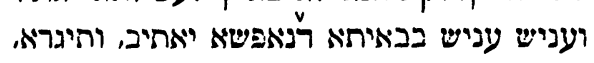

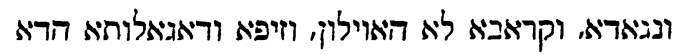

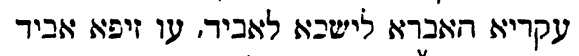

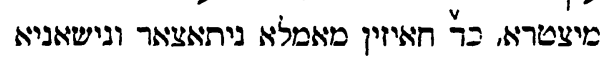

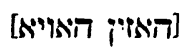

tritt etwas in der Welt ein, sodass Krieg rings umher entsteht, Auserwählte und Trabanten begeben sich in den Kampf, und in diesem Kampfe siegen nur wenige unter ihnen. Und nach ihm entsteht ein neuer König, Sarqid, Sohn des Warzigar ist sein Name; er herrscht sieben Jahre; dann entsteht ein neuer König, dess Name ist Širasp, er herrscht 27 Jahre. Und in den Jahren jener Könige werden die Menschen keine Bosheit kennen, und Streit werden sie nicht erheben, und Erwerb suchen sie nicht, und Speise zum Ueberfluss essen sie nicht, jeder wohnt in einem eigenen Hause, Streit, Marter und Krieg werden sie nicht haben, List und Falschheit gibt es keine, der sie übt gegen seinen Freund, oder eine List begeht, wird bestraft. Wenn diese Rede gebildet wird, [dann werden folgende] Zeichen [eintreten]: 


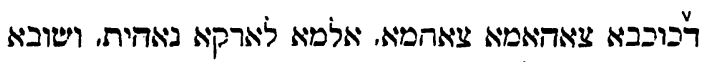

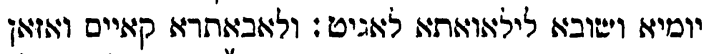

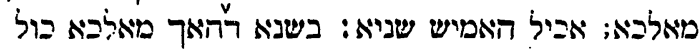

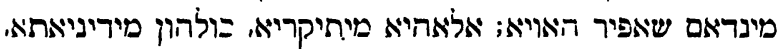

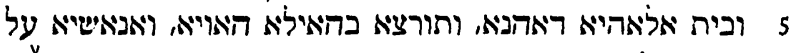

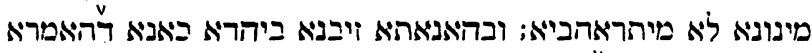

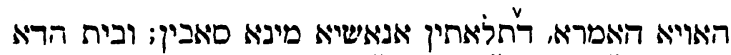

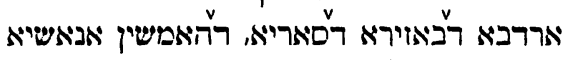

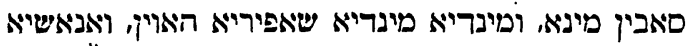

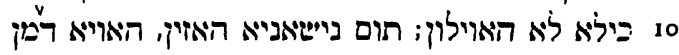

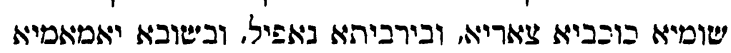

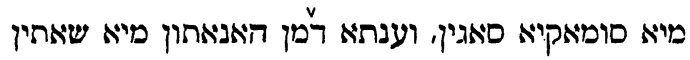

Der glänzende Stern glänzt, bis dass er zur Arqa niedersteigt und sieben Tage und sieben Nächte einnimmt. Nach ihm kommt König Wazan, der herrscht fünf Jahre. In den Jahren dieses Königs geschieht alles, was schön ist, die Götter werden verehrt, alle Städte und Götterhäuser blühen, und die Aufrichtigkeit nimmt zu an Kraft. Die Menschen bereichern sich nicht durch Geld. Und in jener Zeit wird in einem Weinmasse so viel Wein sein, dass 30 Menschen daran genug haben werden; und von einem Masse von Gerstensamen werden 50 Menschen satt werden, und Jedes und Alles wird schön sein, die Menschen werden des Masses nicht bedürfen. Dann werden folgende Zeichen eintreten: Vom Himmel werden die Sterne losgelöst ins Meer fallen, und in den sieben Meeren wird roten Wassers viel sein, und die Weiber, die von jenem Wasser trinken, 
ליא באטנאי ויארינקיא באז/מ[א האויה ועל אניאשיא משאררא

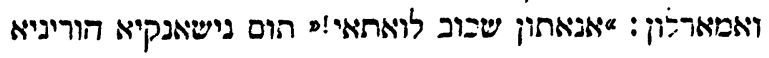

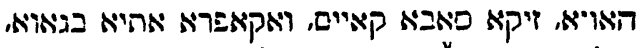

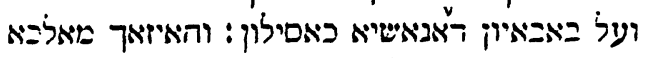

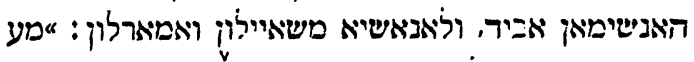

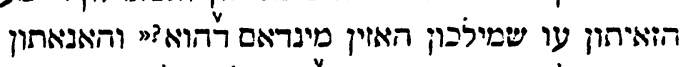

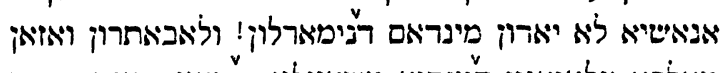

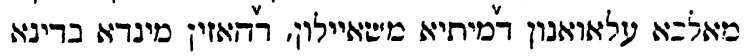

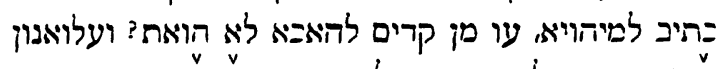

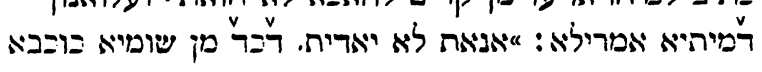

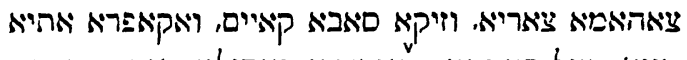

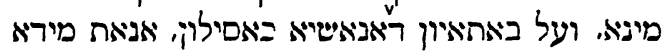

werden nicht schwanger, und sie sind rein in der Welt, und werden geschickt zu den Männern, und sie sprechen zu ihnen: „Ihr da, leget euch zu mir!«. Und dann werden andere Zeichen entstehen, es erhebt sich ein gewaltiger $\mathrm{W}$ ind, und ein Staub kommt herein und bedecket die Tore der Menschen. Und hierauf macht der König eine Versammlung. Er fragt die Leute an und spricht zu ihnen: „Habet ihr etwas gesehen oder darüber etwas gehört, weswegen dies eingetreten?« Jene Männer wissen aber von nichts, das sie sagen könnten. Nach ihnen befragt König Wazan die Geister der Toten, ob dieses etwa im Gerichte verschrieben sei, dass es geschehe, oder ob es früher noch gar nie war? Und die Geister der Toten sprechen zu ihm: „Du weisst es nicht, dass wenn vom Himmel ein Stern sich losreisst, ein starker Sturm entsteht, die Häuser der Menschen bedeckt; 
S. 393,1

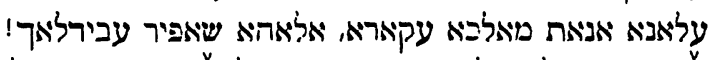

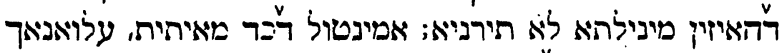

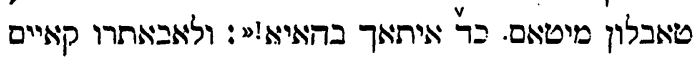

5

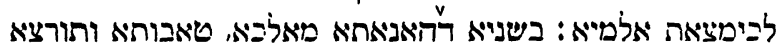

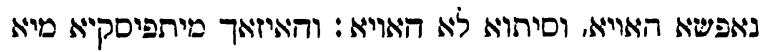

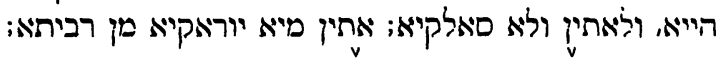

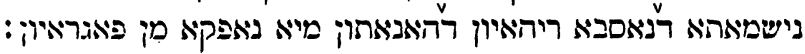

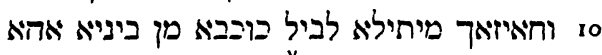

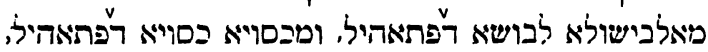

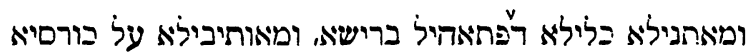

nun sollst du es wissen, dass nach dem Worte des Weltgerichtes du zu dem Frieden gelangest. Du bist, o König. ein herrlicher Geist [Baum]. Gott hat dich herrlich gemacht. Diese Worte sollen dich nicht beunruhigen; denn wenn du stirbst, wirst du ein Baum von gutem Geschmacke, wie du es im Leben warst! N Nach ihm ersteht der König Parušai Sifa, Sohn des Königs Borsin, der regieret bis ans Ende der Welt. In den Jahren jenes Königs werden Wohlstand und Aufrichtigkeit verbreitet sein, und keinen Winter wird es geben. Und hierauf wird das lebende Wasser abgeschnitten und kommt und steigt nicht mehr auf. Es kommt aber grünes Wasser vom Ozean; die Seelen, welche den Dunst jenes Wassers atmen, gehen aus den Leibern hinaus. Und hernach bringt man dem Sterne Bel die Kleider des Petahil, von seinem Bruder, und leget sie ihm an, und hüllt ihn in die Gewänder des Petahil, und man gibt ihm die Krone des Petahil auf sein Haupt, und man setzt ihn auf den Thron 
רִּפהאהיל ארבין ותארתין שניא בהורנא צאריא;

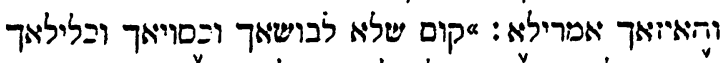
50

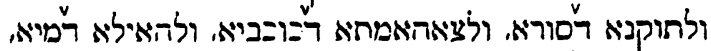

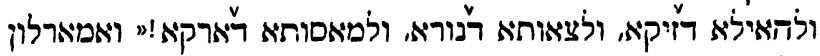

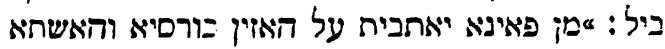

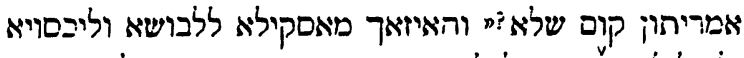

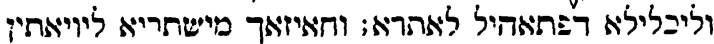

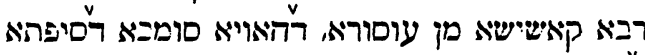

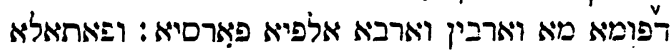

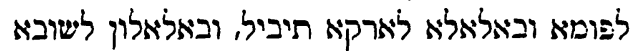

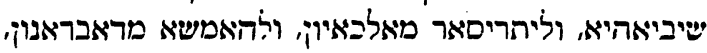

des Petahil 42 Jahre lang in öder Wüste. Und dann sprechen sie zu ihm: Auf! ziehe aus dein Kleid und dein Gewand und deine Krone des Petahil; das, was wir [von dir] wünschen, [ist], sie hinaufzutragen zum Glanze des Šmeš und zur Helle des Mondes, zum Glanze der Sterne und zur Macht des Wassers und zur Kraft des Windes, und zum Glanze des Feuers und zur Verdichtung der Erde.« Da sagt zu ihnen Bel: „Vom Abend an sass ich auf diesem Throne und jetzt saget ihr: 'auf! ziehe [sie] aus!'?" Sie tragen hierauf das Kleid und das Gewand und die Krone des Petahil [wieder] an ihren Ort. Nun wird aber der grosse mächtige Petahil gelöst von seinen Fesseln, dessen Dicke der Lippen seines Rachens I 44000 Parasangen [sind]. Und er öffnet seinen Rachen und verschlinget die ganze Arqa Tebel, und er verschlingt die sieben Gestirne samt ihren zwölf Königen nebst ihren fünf Führern 
S. 394, I

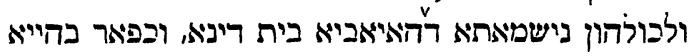

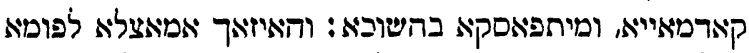

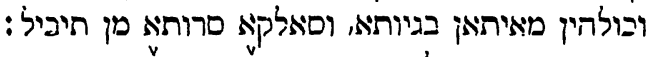
5

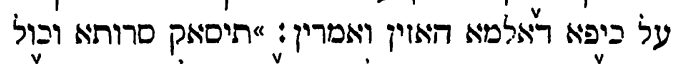

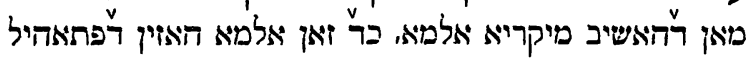

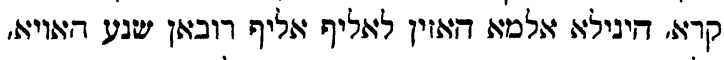

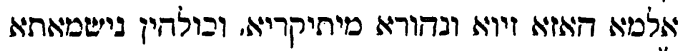

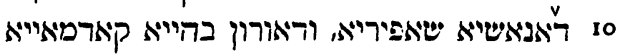

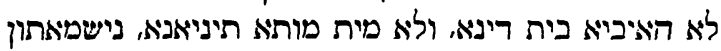

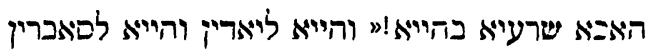

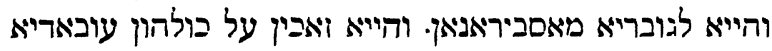

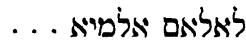

und alle Dämone und Altäre und Götzen und Unholde und Dajwas und Lilits und alle Seelen, die schuldig gesprochen wurden im Gerichte, die da am ersten Leben geleugnet, und sie werden zurückgehalten in der Finsternis. Und hierauf schliesst er seinen Rachen, und alle tötet er sie in seinem Leibe, ein Gestank steigt aber auf aus dem Tebel. Es kommen hierauf alle 'Utras der Arqa des Lichtes und stehen am Strande dieser Welt und sprechen: „Es steige auf ein Gestank von jedem, der da dachte hervorzurufen eine Welt in der Art, wie Petahil diese Welt hervorgerufen, denn diese Welt soll $1000 \times 1000$ Myriaden Jahre bestehen, diese Welt soll als Glanz und Licht geschaffen sein, und alle Seelen der guten Männer, die da weilen im ersten Leben, sollen nicht schuldig gesprochen sein im Gerichte, und nicht sterben einen zweiten Tod, ihre Seelen sollen hier wohnen im Leben! - Und Leben sei den Wisśenden, Leben den Weisen, Leben den lehrenden Männern! Das Leben siegt aber über alle Werke in alle Ewigkeit ... 